
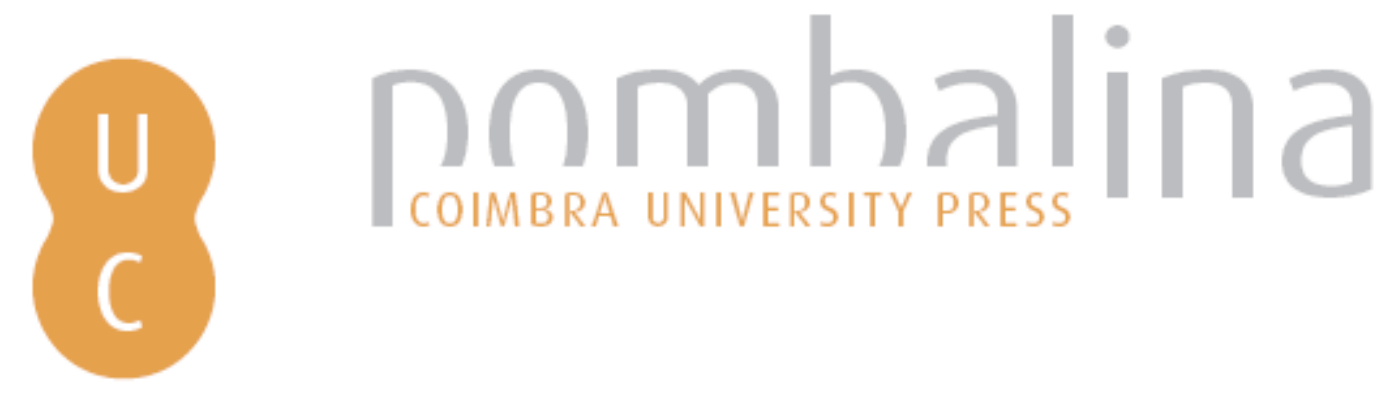

\title{
Panorâmica sobre a estrutura, mineralogia e recursos dos pegmatitos do Linguço em Moçambique
}

\author{
Autor(es): $\quad$ Moiana, M.; Gomes, C. A. L.; Dias, P. \\ Publicado por: Imprensa da Universidade de Coimbra \\ URL \\ persistente: URI:http://hdl.handle.net/10316.2/31443 \\ DOI: $\quad$ DOI:http://dx.doi.org/10.14195/978-989-26-0534-0_28 \\ Accessed : $\quad$ 26-Apr-2023 14:15:19
}

A navegação consulta e descarregamento dos títulos inseridos nas Bibliotecas Digitais UC Digitalis, UC Pombalina e UC Impactum, pressupõem a aceitação plena e sem reservas dos Termos e Condições de Uso destas Bibliotecas Digitais, disponíveis em https://digitalis.uc.pt/pt-pt/termos.

Conforme exposto nos referidos Termos e Condições de Uso, o descarregamento de títulos de acesso restrito requer uma licença válida de autorização devendo o utilizador aceder ao(s) documento(s) a partir de um endereço de IP da instituição detentora da supramencionada licença.

Ao utilizador é apenas permitido o descarregamento para uso pessoal, pelo que o emprego do(s) título(s) descarregado(s) para outro fim, designadamente comercial, carece de autorização do respetivo autor ou editor da obra.

Na medida em que todas as obras da UC Digitalis se encontram protegidas pelo Código do Direito de Autor e Direitos Conexos e demais legislação aplicável, toda a cópia, parcial ou total, deste documento, nos casos em que é legalmente admitida, deverá conter ou fazer-se acompanhar por este aviso.

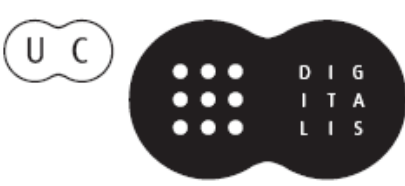





\title{
PANORÂMICA SOBRE A ESTRUTURA, MINERALOGIA E RECURSOS DOS PEGMATITOS DO LICUNGO EM MOÇAMBIQUE
}

\author{
AN OVERVIEW ON STRUCTURE, MINERALOGY AND \\ RESOURCES OF LICUNGO PEGMATITES (MOZAMBIQUE)
}

M. Moiana ${ }^{1,2}$, C. A. L. Gomes ${ }^{1} \&$ P. Dias ${ }^{1}$

\begin{abstract}
Resumo - A mineralogia e a distribuição dos recursos base e reservas do Campo Pegmatítico do Licungo está condicionada, principalmente, a alguns lineamentos estruturais de $1^{\text {a }}$ ordem, de orientação NNE-SSW e NNW-SSE. Estas mega-estruturas acolheram a instalação, no norte, de corpos pegmatíticos de grandes dimensões ( $>3 \mathrm{~m}$ de possança e > $30 \mathrm{~m}$ de extensão), onde a fracionação permitiu a individualização de unidades primárias internas e texturas gráficas na bordadura. Em contrapartida, as estruturas de cisalhamento, provavelmente tardias, no sul, induziram a abertura de menores caixas filoneanas e a instalação de corpos pegmatíticos de pequenas dimensóes (0,25 a 1,20 m de possança e 10-30 m de extensão), com zonas internas menos volumosas mas maior apetência para a ocorrência de berilos da variedade água-marinha, graças à maior capacidade de troca de constituintes entre as rochas encaixantes meta-ultramáficas e os pequenos corpos pegmatíticos.
\end{abstract}

Palavras-chave - Licungo; Pegmatito; Zonalidade; Deformação

Abstract-Mineralogy and distribution of base resources and potential reserves in Licungo Pegmatite Field is mainly related to the position of $1^{\text {st }}$ order structural alignments NNE-SSW and NNW-SSE. These mega-structures allowed the intrusion of major pegmatite bodies (> 3 $m$ in thickness and $>30 \mathrm{~m}$ in length) at the northern sector. Here, paragenetic fractionation was favourable to the individualization of inner primary units and graphic pegmatite at the border. At the southern sector shear-related dilations were probably responsible for the appearance of small pegmatite bodies (0.25-1.20 $\mathrm{m}$ in thickness and 10-30 $\mathrm{m}$ in length) containing thinner primary zones, but with higher content of aquamarine beryl, which might be explained

\footnotetext{
1 CIG-R, Universidade do Minho, Portugal; moiana2000@yahoo.com.br
}

2 Museu Nacional de Geologia, Moçambique; caal.gomes@gmail.com 
by ion exchanges between meta-ultramafic country rocks and small pegmatite bodies, during early emplacement.

Keywords - Licungo; Pegmatite; Zoning; Deformation

\section{1 - Introdução}

O Campo Pegmatítico do Licungo (CPL) está localizado na Província da Zambézia, na região centro de Moçambique. Inclui-se na divisão de Primeira Ordem, Província Pegmatítica Zambeziana e limita a Sul a Cintura Pegmatítica de Monapo-Mocuba.

Vários destes corpos pegmatíticos estão bem expostos em antigos trabalhos de exploração de berilo e $\mathrm{Nb}$-tantalatos e também em trabalhos de pesquisa atuais. Foram objeto de análise estrutural e paragenética os pegmatitos Ígaro (Ig), Vila Maior (VM), Mugulama $(\mathrm{Mg})$, Careca (Cc), Bismuto (Bi), Murribane (Mb), Virgínia (Vg), Scheelite (Sc), Melatube (Mt), Azul Mais (Az) e Lugela (Lg) localizados na fig. 1.

\section{2 - Enquadramento estrutural e assinaturas de filiaçáo}

O CPL constitui parte integrante da Cintura Pegmatítica Monapo-Mocuba, com uma tendência geral de alinhamento NNE-SSW. Os lineamentos da Cintura Pegmatítica são concordantes com aqueles que estruturam o complexo orogénico referido como Cinturão Moçambicano (1100-850 Ma), em cuja cartografia predominam produtos de metamorfismo regional, como gnaisses, migmatitos, granulitos e anfibolitos de idade Proterozoica. O Cinturão Moçambicano ocupa em especial a porçáo Ocidental da Cintura Pegmatítica, podendo constituir a raiz mais proximal dos terrenos mais alóctones que se expandem para Este, onde se encontram, na sua maioria, os corpos pegmatíticos mais evoluídos.

Em geral, os pegmatitos incluem-se na classe de elementos raros, que mostram uma variação espacial de tendências especialização metalogénica, isto é, um carácter NYF envolvente e proximal a Norte, Oeste e Sul, e um carácter LCT mais marcado no centro e na propagação para Este (Fig. 1).

O CPL, em geral, é caracterizado pela ocorrência de pegmatitos de tipo NYF com berilo, contendo minerais típicos desta filiação, como sejam: Nb-tantalatos ricos em molécula columbítica, xenotima, monazite, algum topázio, e ainda, amazonites pertíticas sujeitas a enrubescimento (episienitização incipiente) e rara epidotização. A assinatura potássica é muito marcada - predominância da microclina na fase feldspática. Provavelmente esta assinatura relaciona-se com uma ascendência alcalina relativamente a granitos de tipo A, com morfologia em "stock" ou "plug", que afloram nas proximidades e a Este, em Ethabo. Observam-se, localmente e a Oeste, em Pompisco, algumas raras interposiçóes de tendências evolutivas para uma assinatura LCT incipiente. Também no Norte (Maoloa) e no centro (Vila Maior), se observa uma tendência deste tipo, ainda mais incipiente, expressa em micas zinwaldíticas.

O segmento Alto Ligonha - Alto Molócue, localizado na região central da Cintura Pegmatítica, exibe um carácter LCT muito marcado, correspondente às subclasses variadas 
com lepidolite, espodumena e elbaite (NEIVA \& GOMES, 2011). Os pegmatitos mais conhecidos de Marropino, Morrua, Muiane e Naipa, onde se verifica atividade extrativa dedicada a $\mathrm{Nb}$-tantalatos ricos em molécula tantalítica e gemas variadas, são exemplos claros desta linhagem.

Os pegmatitos de Monapo, inseridos no Distrito Pegmatítico Nampuliano, no extremo norte da referida cintura pegmatítica, de carácter NYF, têm um dispersão que chega à costa marítima e, tal como em Mocuba, apresentam amazonite, columbite>tantalite e berilos azuis.

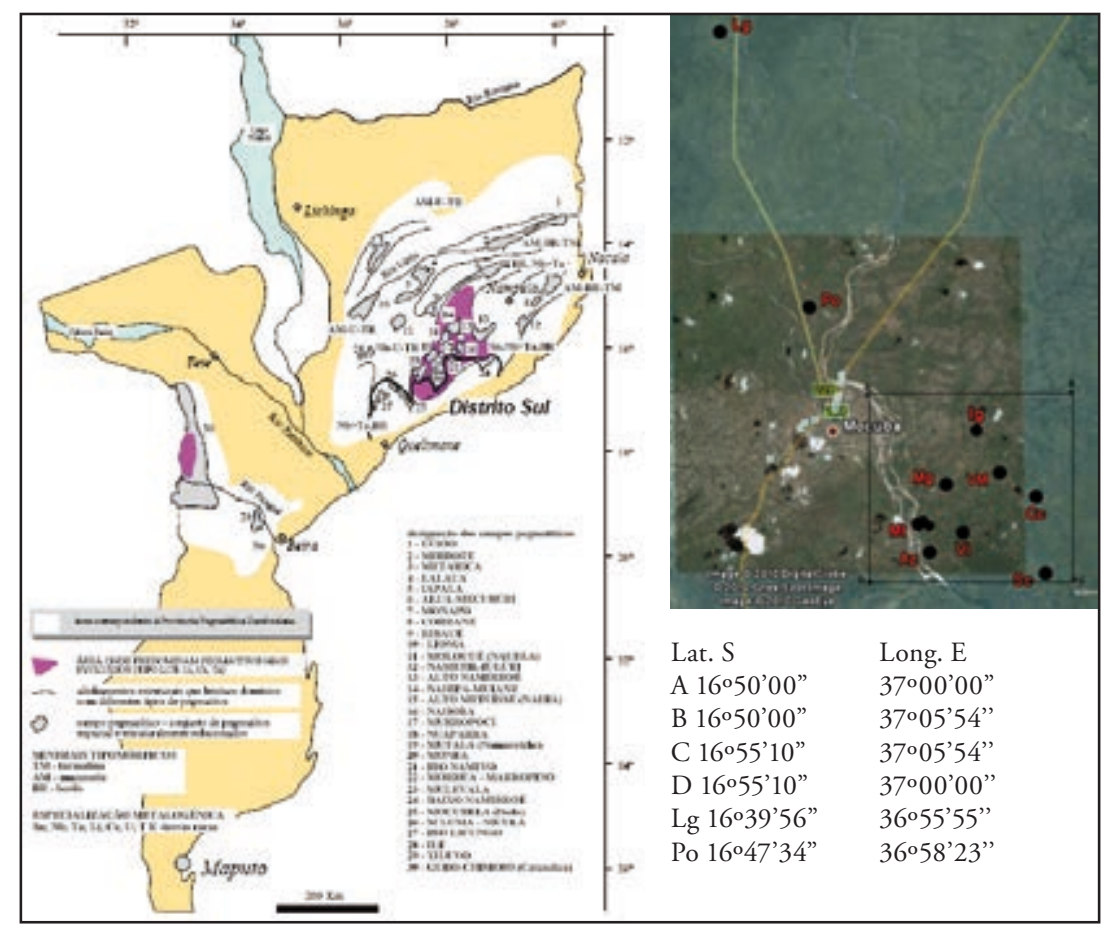

Fig.1 - Localização geográfica do CPL (27 - Rio Licungo) e zonografia das especializaçóes metalogénicas dos pegmatitos da Província Zambeziana. Nota: os símbolos dos pegmatitos da imagem Googlearth estão explicados no texto.

No CPL - Domínio Norte, os alinhamentos estruturais NNE-SSW e NNW-SSE acolheram pegmatitos de grandes dimensóes, tais como Ígaro, Mugulama e Vila Maior, com geometria sub-horizontal ou subvertical, condicionada por ruturas associadas à tectónica tangencial precoce e cavalgamentos sobre o Complexo de Nampula. Estes pegmatitos são atravessados pela superfície $\mathrm{S} n+2$, visível, também, nas rochas encaixantes.

A instalação de corpos pegmatíticos de pequenas dimensões, como Careca, Bismuto, Murribane, Virgínia, Scheelite, Melatube e Azul Mais está associada à tectónica tangencial tardia (DIAS et al., 2008), de tendência WNW-SE e ENE-WSW, que provocou a reativação dos acidentes regionais NNE-SSW e NNW-SSE e "boudinage” mais frequentes no Domínio Sul. 


\section{3 - Estrutura interna e tipologia dos pegmatitos}

Independentemente da sua dimensão, a estrutura interna dos pegmatitos do Licungo é

muito simples e persistente. Caracteriza-se pela existência de bordos espessos de pegmatito gráfico, zonas intermédias ricas em pertite e núcleos de quartzo volumosos. Trata-se de pegmatitos com morfologia lenticular a tabular (Fig. 2), de orientação NW-SE a NNW-SSE para o caso dos corpos Mugulama, Melatube, Vila Maior, Murribane e Azul Mais, e NNE-SSW para Vila Maior e Careca.

Os corpos Vila Maior, Melatube e Lugela são os mais representativos e, por isso, são descritos, de forma mais pormenorizada, em seguida.

\section{1 - Vila Maior}

O pegmatito de Vila Maior está limitado a sul por um carreamento de muito baixo ângulo, com direção predominante WSW-ENE, o qual, provavelmente, condicionou a intrusão pegmatítica. O pegmatito é zonado, destacando-se a presença de uma grande massa com textura gráfica na zona de bordadura, onde se individualizam alguns gigafeldspatos intercrescidos com biotite. Existe uma zona intermédia, onde predomina a microclina pertítica, e o núcleo de quartzo é volumoso, possuindo ocasionais cavidades miarolíticas parcialmente preenchidas por feldspatos automórficos, cristais de quartzo e argilas.

As rochas encaixantes, a $\mathrm{N}$ do carreamento principal, são gneissico-anfibólicas ou anfibolíticas bandadas. A sul predominam os paragneisses com magnetite.

Ocorrem alguns corpos satélites, com ligeiras variações paragenéticas, como por exemplo o corpo situado a cerca de $150 \mathrm{~m}$ para NE, fortemente meteorizado, que inclui paragéneses mais evoluídas com quartzo \pm micas de $\mathrm{Li} \pm$ albite e, localmente, columbite e berilo amarelo (associado a minerais metamícticos).

As unidades de substituição mais frequentes são faixas greisenosas, com moscovite por vezes grosseira, apresentando uma localização controlada por estruturas frágeis sobrepostas (DIAS \& GOMES, 2006).

\section{2 - Melatube}

O pegmatito de Melatube tem uma morfologia em rosário composta por "boudins" orientados segundo o azimute WNW-ESE, subconcordante com a foliação regional NW-SE, a mais penetrativa da evolução tectono-metamórfica verificada entre os eventos tardi-Kibariano e Panafricano (DIAS et al., 2008). Os "boudins" individuais são zonados, com bordaduras espessas de pegmatito gráfico com biotite e granada, zona intermédia com blocos de pertite, muito raramente amazonítica, e núcleos de quartzo maciços.

Nas proximidades, os corpos Murribane e Virginia apresentam alteração pósmagmática expressa por argilização e metassomatismo dos feldspatos (epissienitizaçáo e presença de feldspatos rubros cavernosos), que contrasta com a moscovitização e albitização com minerais acessórios de $\mathrm{Bi}, \mathrm{Nb}$ e Ta que são mais típicos de Melatube. Mais para $\mathrm{E}$, um corpo de pequenas dimensóes, o pegmatito Vieira, encontra-se dobrado em dúctil de 
forma concordante com o último episódio dos dobramentos polifásicos que se observam nos gnaisses e migmatitos encaixantes.

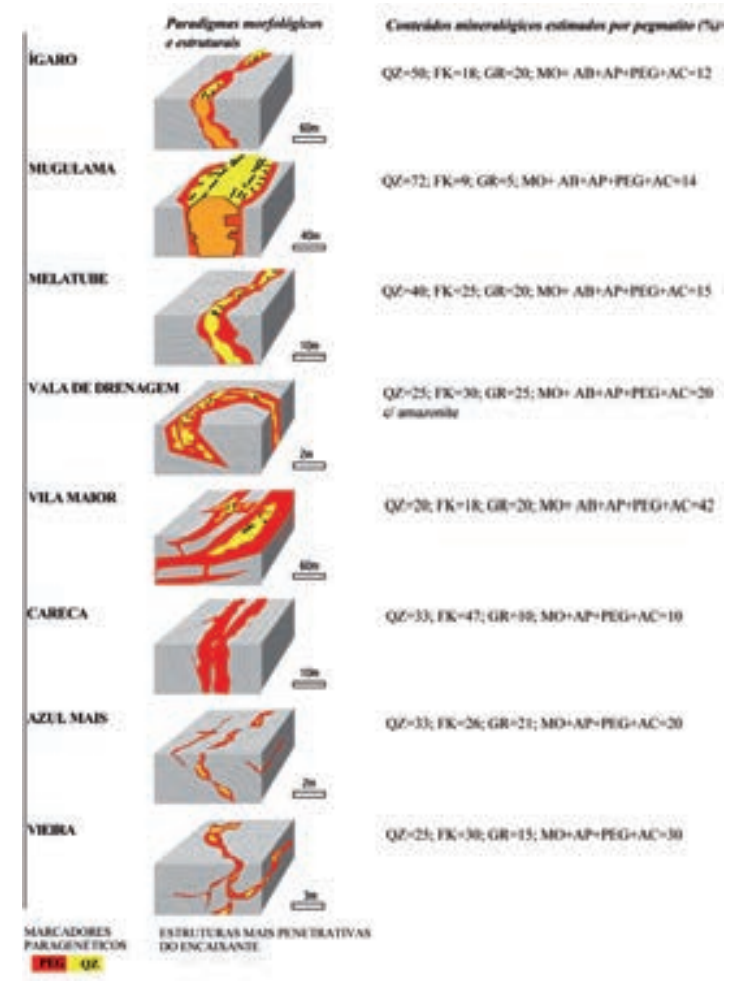

Fig. 2 - Modelos morfológicos e estruturais dos tipos paradigmáticos de pegmatitos do Licungo. FK - feldspato potássico; GR - granada; $M O$ - moscovite; AP - fácies aplítica; PEG - fácies pegmatítica; $\mathrm{AB}$ - albite; QZ - quartzo; AC - acessórios incluindo minérios e gemas (GOMES, 2009).

\section{3 - Lugela}

Os pegmatitos de Lugela têm grandes dimensôes e mostram uma grande variação espacial das suas paragéneses representativas. Na localidade tipo, Pompisco, ocorrem corpos com grandes núcleos de quartzo, frequentemente hialino, que transita lateralmente para quartzo róseo. Nas zonas intermédias ocorre a associação feldspato-K+quartzo+lepidolite e a bordadura é marcada pela textura gráfica.

No mesmo conjunto inclui-se o pegmatito de Munhamade, lenticular e com orientação NW-SE, instalado em rochas encaixantes ortognaissicas. Tem zonamento indistinto, mas apresenta uma unidade feldspática espessa $(>2 \mathrm{~m})$, que transita lateralmente para uma associação quartzo+microclina \pm biotite. Destaca-se a ocorrência de gigacristais $(>140 \mathrm{~kg})$ muito fracturados de berilo nas frentes de transição entre feldspato e quartzo tendencialmente hialino o qual, localmente, se torna ametista. 


\section{4 - Recursos base}

A valorização dos recursos disponíveis no CPL poderá passar pelo planeamento da exploração integral das reservas de quartzo e feldspato de qualidade cerâmica presentes em todos os corpos pegmatíticos, apurando, como subprodutos, os nióbio-tantalatos e as gemas, em especial, as águas marinhas.

Assim, podem considerar-se viáveis as seguintes categorias de matérias-primas minerais:

1. águas-marinhas - a sua qualidade (transparência e dimensão) e a intensidade da cor azul estáo condicionadas à posição estrutural dos pegmatitos; localmente associados, ocorrem o heliodoro, almandina e espessartite e aparecem indícios de fenacite, euclase e crisoberilo (GOMES, 2009);

2. minérios - nióbio-tantalatos são comuns em Ígaro e Vila Maior, estando associados a mineralizações de Ti, Y, Terras Raras, U e Th (DIAS \& GOMES, 2006) e magnetite, tanto nos pegmatitos, como em depósitos de tipo placer, proximais;

3. minerais industriais - além do quartzo e feldspatos, minerais industriais mais comuns, é de se considerar o eventual aproveitamento de berilo industrial. GOMES (2009) refere-se à possibilidade de aproveitamento de recursos de pegmatito gráfico.

Na tabela 1 apresentam-se as mineralizaçóes típicas e acessórias de alguns corpos pegmatíticos estudados em Licungo (DIAS \& GOMES, 2006).

Tabela 1 - Quadro resumo da mineralização de alguns pegmatitos do Licungo (DIAS \& GOMES, 2006).

\begin{tabular}{|c|c|c|}
\hline Ocorrências & $\begin{array}{l}\text { Minerais essenciais e } \\
\text { mineralizaçôes típicas }\end{array}$ & $\begin{array}{l}\text { Minerais acessórios e variedades raras } \\
\text { de minerais essenciais }\end{array}$ \\
\hline Vila Maior & $\begin{array}{l}\text { Quartzo > pertite > albite, } \\
\text { berilo industrial }\end{array}$ & $\begin{array}{l}\text { Monazite, xenotima, brabantite, samarskyte, betafite, } \\
\text { alanite, fersmite, fergusonite, aeshynite, wodginite, } \\
\text { rynnersonite, columbite - tantalite, Ti - ixiolite, } \\
\text { pirocloro, } \mathrm{U}, \mathrm{Pb} \text { - microlite, cheralite, amazonite. }\end{array}$ \\
\hline Mugulama & $\begin{array}{l}\text { Quartzo >> pertite > albite, } \\
\text { berilo }\end{array}$ & $\begin{array}{l}\text { Magnetite, ilmenite, rútilo, granada (Mn-almandina), } \\
\text { quartzo óptico. }\end{array}$ \\
\hline Ígaro & $\begin{array}{l}\text { Quartzo > pertite >> albite, } \\
\text { berilo industrial e gema }\end{array}$ & $\begin{array}{l}\text { Columbite-tantalite, euxenite-policrase, monazite, } \\
\text { cheralite, ilmenite e bismutite, F-apatite, amazonite. }\end{array}$ \\
\hline Melatube & $\begin{array}{l}\text { Quartzo > pertite }>>\text { albite, } \\
\text { berilo azul escuro, bismutini- } \\
\text { te, molibdenite e bismutite }\end{array}$ & $\begin{array}{l}\text { Água marinha, struverite, tantalite, microlite, } \\
\text { Fe-columbite, monazite, xenotima, F-apatite, } \\
\text { alanite, fenakite, bertrandite, "sunstone". }\end{array}$ \\
\hline Murribane & $\begin{array}{l}\text { Quartzo }<\text { microclina }<< \\
\text { albite, magnetite }\end{array}$ & $\begin{array}{l}\text { Cheralite, monazite, xenotima, ilmenite, rútilo, } \\
\text { granada, pistacite. }\end{array}$ \\
\hline Bismuto & $\begin{array}{l}\text { Quartzo < pertite > albite, } \\
\text { bismutite }\end{array}$ & $\begin{array}{l}\text { Berilo, cheralite, monazite, xenotima, ilmenite, } \\
\text { ilmenorútilo, columbo-tantalite. }\end{array}$ \\
\hline Vieira & $\begin{array}{l}\text { Quartzo > pertite >> albite, } \\
\text { berilo azul escuro gema }\end{array}$ & Zircâo, monazite, xenotima, ilmenite, rútilo. \\
\hline Azul Mais & $\begin{array}{l}\text { Quartzo > pertite >> albite, } \\
\text { berilo azul escuro gema }\end{array}$ & Zircâo, monazite, xenotima. \\
\hline Careca & Quartzo $<<$ pertite $>>$ albite & Euclase \\
\hline Lugela & $\begin{array}{l}\text { Quartzo > feldspato }>>\text { albite, } \\
\text { berilo industrial }\end{array}$ & Ilmenite, "schorl". \\
\hline
\end{tabular}




\section{5 - Consideraçóes finais}

O CPL enquadra-se no extremo sul da cintura pegmatítica Monapo-Mocuba, estabelecida segundo lineamentos regionais NNE-SSW, análogos aos eixos de afloramento das intrusóes graníticas Pan-Africanas e lineamentos do Cinturão Moçambicano.

Os pegmatitos correspondem à linhagem NYF e foram provavelmente diferenciados a partir de um magma granítico de tendência alcalina, cujas fácies representativas afloram a este do CPL na região de Ethabo.

A evolução tectónica regional facultou a instalação de corpos pegmatíticos de grandes dimensóes no Setor N do CPL em relação com carreamentos e ruturas distensivas de baixo ângulo - aqui é possível individualizar reservas de feldspatos e quartzo com apetência vitro-cerâmica. Em contrapartida, cisalhamentos tardios ligados a deslocamento transcorrente no Setor Sul, induziram a abertura de pequenas caixas filoneanas e a instalação de corpos pegmatíticos de pequenas dimensôes, contendo unidades internas menos possantes mas maior apetência para a produção de águas-marinhas de cor intensa, graças à maior capacidade de troca de constituintes entre as rochas encaixantes e os pegmatitos de menores dimensões.

Agradecimentos - O presente trabalho recebeu apoio da Fundação Calouste Gulbenkian, através de uma bolsa de doutoramento (P-119860 (M)), e do Museu Nacional de Geologia de Moçambique para a realização dos trabalhos de campo.

\section{Referências Bibliográficas}

DIAS, P. A. \& GOMES, C. A. L. (2006) - Reconhecimento Geológico e Cartografia do Sítio Mineiro Vila Maior (Mocuba, Moçambique) - Aplicaçâo da Mineralometria ao Cálculo de Reservas de Concentrados de $\mathrm{Nb}-\mathrm{Ta}$ - Relatório inédito para grupo de empresas SOMIPE \& SOMINA, 11 p.

DIAS, P. A., GOMES, C. A. L. \& MARQUES, J. (2008) - Caracterização estrutural e paragenética do Campo Pegmatítico do Licungo (Mocuba, Moçambique) - Identificação de recursos base Associados. $5^{\circ}$ Congresso Luso-Moçambicano de Engenharia//2 Congresso de Engenharia de Moçambique, 6 p.

GOMES, C. A. (2009) - Reavaliação dos Recursos de Materiais Cerâmicos Pegmatíticos na Área de Influência do Campo Pegmatítico do Licungo, Zambézia, Moçambique. Relatório inédito elaborado no âmbito do protocolo de cooperação entre CIG-R (Universidade do Minho, Portugal) e AGS (Prospecção e Pesquisa Mineral - Mocuba, Moçambique), 8p.

NEIVA, A. M. R. \& GOMES, C. A. L. (2011) - Tourmaline-group minerals in the Naipa Li-Cs-Ta granitic pegmatite group, Mozambique: tracers of magmatic to postmagmatic evolution trends N. Jb. Miner. Abh. 189/1, p. 1-20. 